\title{
Risk Factor for Transient Hyperopic Refractive Outcome at Acute Postoperative Period After Panoptix Intraocular Lens Implantation
}

\author{
Sohee Jeon \\ Ayoung Choi \\ Keye Eye Center, Seoul, Korea
}

Correspondence: Sohee Jeon

Keye Eye Center, 326 Teheran-ro,

Gangnam-gu, Seoul, Korea

Tel +82-02-6207-I 236

Fax +82-02-6207-1 246

Email soheeeee@gmail.com
Purpose: To evaluate transient hyperopic refractive outcomes after Acrysof IQ Panoptix TFNT intraocular lens (IOL) implantation and risk factors for transient hyperopia.

Methods: This was a retrospective case review conducted from July 5, 2019, to February 28, 2020, of 203 eyes from 203 patients. The spherical equivalent (SE) on postoperative day 1 , week 1 , month 1 , month 2 , and month 6 was evaluated, and the difference between SE (dSE) on postoperative day 1 and month 6 was calculated. Ocular parameters that were associated with a high dSE were evaluated.

Results: This study evaluated 203 eyes from 203 patients (mean age \pm SD, $59.14 \pm 5.78$ years; 129 women [63.5\%]). The $\mathrm{dSE} \pm \mathrm{SD}$ was $0.07 \pm 0.30 \mathrm{D}, 0.14 \pm 0.34 \mathrm{D}, 0.12 \pm 0.35 \mathrm{D}$, and $0.08 \pm 0.35 \mathrm{D}$ for postoperative week 1 , month 1 , month 2 , and month 6 , respectively. Univariate analysis revealed that the anterior chamber depth and white-to-white (WTW) corneal diameter were associated with a larger $\operatorname{dSE}(P=0.048$ and $P=0.03$, respectively). Multivariate analysis showed that the WTW diameter was independently associated with the large amount of dSE at 6 months $(r=-0.162 ; P=0.03)$.

Conclusion: The results of this study suggest that a smaller WTW corneal diameter was associated with a large dSE between postoperative day 1 and postoperative month 6 .

Keywords: axial length, hyperopia, intraocular lens, multifocal intraocular lens, myopia

Among the factors that contribute to patient satisfaction after multifocal intraocular lens (MIOL) implantation, an emmetropic refractive outcome is the most critical factor of all. ${ }^{1-3}$ Acrysof IQ Panoptix TFNT IOL (Alcon Laboratories, Inc, Fort Worth, Texas, United States), which is one of the most commonly used diffractive MIOLs, has consistently shown favorable clinical outcomes. ${ }^{4-8}$ The refractive outcomes of the TFNT IOL using modern IOL formulas for eyes with an axial length (AL) within the normal range (ie, $22-25 \mathrm{~mm}$ ) have been favorable; $93 \%$ to $100 \%$ of the eyes were within $\pm 0.50 \mathrm{D}$ of the intended correction. ${ }^{6-8}$

The accuracy of IOL calculations is suboptimal for small eyes (ie, AL < $22 \mathrm{~mm}),{ }^{2,9,10}$ as the most accurate formulas provide results within $\pm 0.5 \mathrm{D}$ of the target in less than $75 \% .{ }^{9}$ We found in previous studies that the modern theoretical IOL formulas predicted myopic refractive outcomes after TFNL IOL implantation in hyperopic eyes, particularly when there was deviation from standard ocular parameters, such as a large white-to-white (WTW) corneal diameter in eyes with short AL. ${ }^{11}$ In addition to those cases that resulted in an inaccurate prediction of postoperative refraction, there are a certain proportion of patients who experience 
transient hyperopia during the acute postoperative period and then return to the targeted refraction over the long term. It is important to distinguish patients with transient hyperopia from patients with inaccurate IOL calculation when deciding on the target refractive power of the other eye. In the present study, we analyzed the changes in the refractive outcomes after TFNT IOL implantation, and we evaluated the patients at risk of transient hyperopic outcomes.

\section{Methods}

We reviewed the medical records of patients who underwent phacoemulsification and TFNT IOL implantation from July 5, 2019, to February 28, 2020, at Keye Eye Center, Seoul, Korea. All eye surgeries were performed by an experienced surgeon (S.J.) using a standard sutureless 2.2- $\mathrm{mm}$ microincision and a 5.2- $\mathrm{mm}$ diameter continuous curvilinear capsulorrhexis using a femtosecond laser (LENSAR, Orlando, Florida, United States). Eyes with underlying retinal disease, previous corneal or vitreoretinal surgery, intraoperative capsular damage, or postoperative cystoid macular edema, were excluded from the analysis. The Institutional Review Board (IRB)/Ethics Committee of KEYE Eye Center (IRB number P12361001-001) approved the study and waived the requirement for informed consent because of the retrospective nature of the study. All data were anonymized prior to the analysis. The study protocol adhered to the tenets of the Declaration of Helsinki.

\section{IOL Power Calculation and Outcome Measure}

In most of the study cases, the IOL power was selected to target emmetropia by choosing the first negative power IOL based on the Barrett Universal II formula in the IOLMaster 700 (Carl Zeiss Meditec) using total keratometry mode. We implanted toric IOL in eyes with corneal astigmatism higher than 0.50 D. For all calculations, a surgically induced astigmatism of 0.20 was used. Lens constant optimizations for the TFNT IOL were performed in collaboration with Carl Zeiss Meditec AG.

Comprehensive preoperative ocular examinations were routinely performed, including uncorrected and corrected distance visual acuity (UDVA and CDVA), uncorrected and corrected near visual acuity (UNVA and CNVA), refractive error, slit-lamp examination, IOLMaster 700 (software version 1.88), corneal topography using the
Pentacam Scheimpflug System (Oculus Optikgeräte $\mathrm{GmbH}$ ), ultra-widefield fundus photography (Optos Optomap Panoramic 200A Imaging System; Optos plc, Dunfermline, Scotland), and spectral-domain OCT (SDOCT) version 5 (Heidelberg Engineering, Heidelberg, Germany). Monocular near visual acuities were measured using the Sloan ETDRS Format Near Vision chart 3 with $100 \%$ contrast under photopic conditions (85 candelas $[\mathrm{cd}] / \mathrm{m}^{2}$ ) at $40 \mathrm{~cm}$. The UDVA, CDVA, UNVA, CNVA, and refraction were done at postoperative day 1 , week 1 , month 1 , month 2 , and month 6 .

We wanted to evaluate whether there was a difference in spherical equivalent (dSE) between postoperative day 1 and postoperative month 6 . All manifest refractions were performed by 1 of 5 experienced optometrists using trial lenses. The dSE was calculated by subtracting the spherical equivalent (SE) on month 6 from the SE measured on day 1 . The secondary goal of this study was to analyze the factors associated with a large dSE.

\section{Statistical Analysis}

Statistical analyses were conducted using SPSS, version 15.0 for Windows (SPSS, Inc., Chicago, IL, United States). Pupil size and WTW corneal diameter from Pentacam Scheimpflug System, AL, mean keratometric value $(\mathrm{Km})$, keratometric astigmatism $(\mathrm{Ka})$, anterior chamber depth (ACD), lens thickness (LT) from IOLmaster, and preoperative SE were used for the analysis. The Pearson correlation coefficient was used to assess the association between continuous variables, according to the normality of distribution. The Shapiro-Wilk test was used to assess normality of the continuous variables. Independent variables significantly associated with scores in univariate analyses $(P<0.05)$ and potentially confounding parameters were included as independent covariables in multivariate analyses by multiple regression analysis. A $P$ value $<0.05$ was considered significant.

\section{Results}

This study evaluated 203 eyes from 203 patients (mean age $\pm \mathrm{SD}, 59.14 \pm 5.78$ years; 129 women [63.5\%]). Table 1 shows the baseline characteristics of the enrolled patients. Figure 1 shows the postoperative SE. The mean $\mathrm{SE} \pm$ on postoperative day 1 was $0.02 \pm 0.36 \mathrm{D}$ and significantly decreased to $-0.05 \pm 0.33 \mathrm{D}(P=0.001),-0.12 \pm 0.69$ $\mathrm{D}(P<0.001),-0.10 \pm 0.38 \mathrm{D}(P<0.001)$, and $-0.06 \pm$ $0.39 \mathrm{D}(P=0.001)$ on postoperative week 1 , month 1 , month 2 , and month 6 , respectively. The dSE was $0.07 \pm$ 
Table I Characteristics of Patients Enrolled in the Study $(n=203)$

\begin{tabular}{|l|l|}
\hline Characteristics & Data \\
\hline Age (years) & $59.14 \pm 5.78$ \\
\hline Sex (female, \%) & $129(63.5)$ \\
\hline Eyes (OD, \%) & $101(49.8)$ \\
\hline Pupil size (mm) & $2.88 \pm 0.48$ \\
\hline SE (D) & $-0.32 \pm 3.41$ \\
\hline AL (mm) & $23.49 \pm 1.48$ \\
\hline Km (D) & $44.38 \pm 1.31$ \\
\hline Ka (D) & $-0.85 \pm 0.56$ \\
\hline ACD (mm) & $3.06 \pm 0.39$ \\
\hline LT (mm) & $4.50 \pm 0.36$ \\
\hline WTW (mm) & $11.37 \pm 0.36$ \\
\hline
\end{tabular}

Abbreviations: $A C D$, anterior chamber depth; $A L$, axial length; $K a$, keratometric astigmatism; Km, mean keratometric value; LT, lens thickness; $S E$, spherical equivalent; WTW, white to white corneal diameter.

$0.30 \mathrm{D}$ (range, -0.88 to $1.11 \mathrm{D}$ ), $0.14 \pm 0.34 \mathrm{D}$ (range, 1.27 to $0.97 \mathrm{D}$ ), $0.12 \pm 0.35 \mathrm{D}$ (range, -0.83 to $1.51 \mathrm{D}$ ), and $0.08 \pm 0.35 \mathrm{D}$ (range, -1.08 to $1.53 \mathrm{D}$ ) on postoperative week 1 , month 1 , month 2 , and month 6 , respectively. We evaluated the ocular factors associated with the amount of dSE at 6 months (Table 2). Univariate analysis revealed that anterior chamber depth and WTW diameter were associated
Table 2 Association of Patient Characteristics with the Amount of Transient Hyperopic Refraction ( $n=203)$

\begin{tabular}{|l|l|l|l|l|}
\hline Characteristics & \multicolumn{2}{|l|}{$\begin{array}{l}\text { Univariate } \\
\text { Analysis }\end{array}$} & \multicolumn{2}{l|}{$\begin{array}{l}\text { Multivariate Analysis } \\
(\mathbf{R}=\mathbf{0 . 1 6 2})\end{array}$} \\
\hline & p value & $\mathrm{r}$ & $\mathrm{P}$ value & $\beta$ \\
\hline Age (years) & 0.489 & -0.049 & & \\
\hline Pupil size (mm) & 0.530 & 0.044 & & \\
\hline SE (D) & 0.329 & 0.069 & & \\
\hline AL (mm) & 0.212 & -0.088 & & \\
\hline Km (D) & 0.177 & 0.095 & & \\
\hline Ka (D) & 0.194 & 0.093 & & \\
\hline ACD (mm) & 0.048 & 0.139 & & \\
\hline LT (mm) & 0.229 & -0.032 & & \\
\hline WTW (mm) & 0.030 & -0.158 & 0.028 & -0.162 \\
\hline
\end{tabular}

Abbreviations: $A C D$, anterior chamber depth; $A L$, axial length; $K a$, keratometric astigmatism; Km, mean keratometric value; LT, lens thickness; SE, spherical equivalent, WTW, white to white corneal diameter.

with a larger $\operatorname{dSE}(P=0.048$ and $P=0.03$, respectively). Multivariate analysis showed that the WTW was independently associated with a large dSE at postoperative month 6 after adjustment for age and $\mathrm{AL}(r=-0.162 ; P=0.03)$. The patients with a smaller WTW corneal diameter exhibited a larger difference in the SE between postoperative day 1 and month 6 (Figure 2).

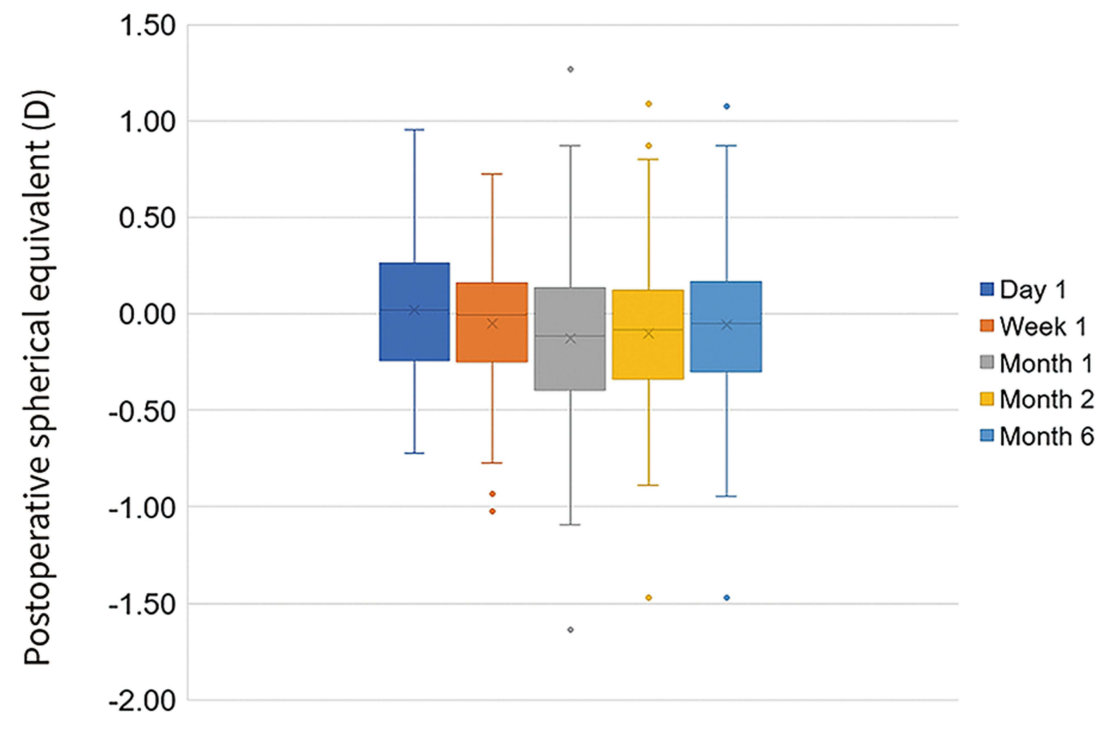

Time course

Figure I Bar graphs showing refractive outcome at postoperative day I, week I, and months I, 2, and 6. 


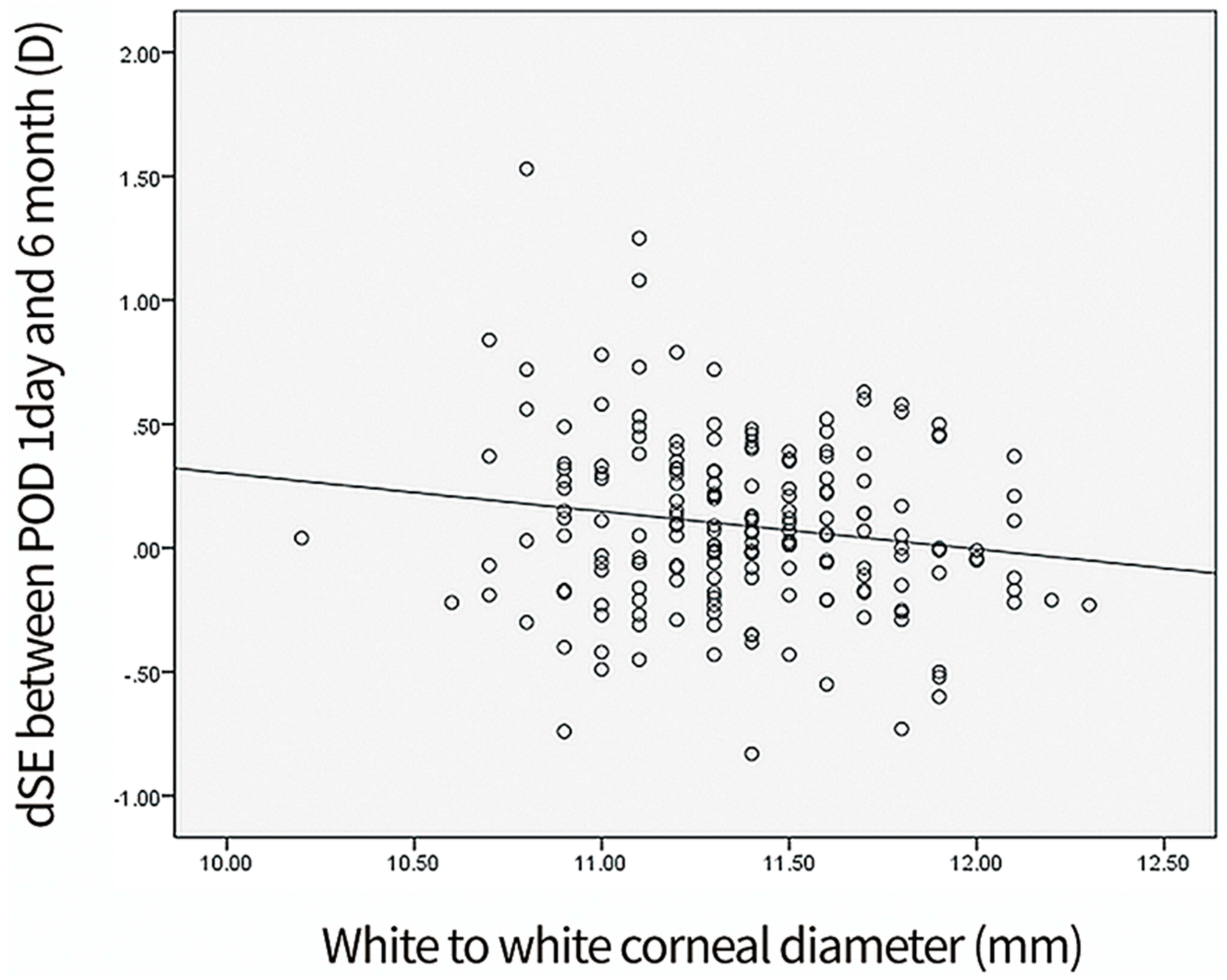

Figure 2 Dot graph for the association between white-to-white (WTW) corneal diameter and the difference in the spherical equivalent between postoperative day I and month 6.

\section{Discussion}

In the present study, results suggest that eyes with a small WTW diameter were associated with a transient hyperopic state during the acute postoperative period. We speculate that this may be because eyes with small WTW diameters have a small capsular diameter that may result in a bending of the optic-haptic junction during the acute postoperative period, which could then normalize over time. Results also suggest that the large WTW diameter in short eyes was associated with a greater prediction error when using the Barrett Universal II formula, which is one of the most accurate IOL formulas available thus far. ${ }^{11}$ This led us to two potential reasons why the SE during the acute postoperative period was more hyperopic than expected: (1) a real prediction error or (2) a transient hyperopic state. The distinction between these two possibilities is critical when the surgery of the other eye has to be planned immediately, as many surgeons determine the target diopter of fellow eye according to the refractive outcome of the operative eye. Misinterpretation of the results could lead to an unwanted myopic refractive outcome in the fellow eye that may require IOL exchange or corneal ablation. The WTW diameter could help to discriminate a transient hyperopic state from a real prediction error.

We speculate that the cause of a transient hyperopic state during the acute postoperative period may arise from changes in the position of IOL optic. In a previous study using postmortem human eyes, the lens diameter showed a significant correlation with WTW diameter with a correlation coefficient of 0.711 ; the mean corneal diameter $\pm \mathrm{SD}$ was $11.59 \pm 0.42 \mathrm{~mm}$, and the mean lens diameter \pm SD was $9.54 \pm 0.27 \mathrm{~mm} .{ }^{12}$ Because the TFNT IOL is $13.0 \mathrm{~mm}$ in diameter, the optic-haptic junction may 
bend during the acute postoperative period in eyes with a small lens capsule diameter. The pupil size also can affect the postoperative refraction of many MIOLs according to the optic design. However, the postoperative refraction of TFNT IOL is not affected by pupil size, which helped us to rule out the role of pupil size as a potential etiology for the transient hyperopic state.

The transient hyperopia after cataract surgery has been discussed in the previous literature, with inconsistent outcomes according to the optic-haptic design and IOL materials. ${ }^{13-16}$ In general, one-piece IOLs show more stable ACD than three-piece IOL. ${ }^{13,14}$ In addition, a newly introduced IOL (Clareon ${ }^{\circledR}$ CNA0T0, Alcon Laboratories Inc) that used hydrophilic copolymer and 2-hydroxyethylmethacrylate instead of phenyl-ethyl methacrylate which is used in AcrySof IOL showed stable ACD and SE from postoperative day 1 to month $3 .^{16}$

The accuracy of the modern IOL formula when using a TFNT IOL is favorable. ${ }^{11}$ Although the absolute refractive difference between that measured on postoperative day 1 and postoperative month 6 was as small as $0.08 \mathrm{D}$, the largest amount of the refractive difference was 1.53 D. Because even a small amount of postoperative refractive error can significantly affect visual outcome and patient satisfaction, it would be helpful to discriminate those patients at risk of a transient hyperopic state. This analysis was limited to TFNT IOLs; therefore, the results could not be extended to other types of IOLs.

\section{Funding}

There is no funding to report.

\section{Disclosure}

The authors report no conflicts of interest in this work.

\section{References}

1. Koch DD, Hill W, Abulafia A, Wang L. Pursuing perfection in intraocular lens calculations: i. Logical approach for classifying IOL calculation formulas. J Cataract Refract Surg. 2017;43(6):717-718. doi:10.1016/j.jcrs.2017.06.006

Clinical Ophthalmology

\section{Publish your work in this journal}

Clinical Ophthalmology is an international, peer-reviewed journal covering all subspecialties within ophthalmology. Key topics include: Optometry; Visual science; Pharmacology and drug therapy in eye diseases; Basic Sciences; Primary and Secondary eye care; Patient Safety and Quality of Care Improvements. This journal is indexed on PubMed

Submit your manuscript here: https://www.dovepress.com/clinical-ophthalmology-journal
2. Melles RB, Holladay JT, Chang WJ. Accuracy of Intraocular Lens Calculation Formulas. Ophthalmology. 2018;125(2):169-178. doi:10.1016/j.ophtha.2017.08.027

3. Kane JX, Van Heerden A, Atik A, Petsoglou C. Accuracy of 3 new methods for intraocular lens power selection. $J$ Cataract Refract Surg. 2017;43(3):333-339. doi:10.1016/j.jcrs.2016.12.021

4. Marques EF, Ferreira TB. Comparison of visual outcomes of 2 diffractive trifocal intraocular lenses. $J$ Cataract Refract Surg. 2015;41(2):354-363. doi:10.1016/j.jcrs.2014.05.048

5. Kohnen T, Titke C, Böhm M. Trifocal intraocular lens implantation to treat visual demands in various distances following lens removal. Am J Ophthalmol. 2016;161:71-7.e1. doi:10.1016/j.ajo.2015.09.030

6. Lawless M, Hodge C, Reich J, et al. Visual and refractive outcomes following implantation of a new trifocal intraocular lens. Eye Vis (Lond). 2017;4:10. doi:10.1186/s40662-017-0076-8

7. Kohnen T, Herzog M, Hemkeppler E, et al. Visual performance of a quadrifocal (trifocal) intraocular lens following removal of the crystalline lens. Am J Ophthalmol. 2017;184:52-62. doi:10.1016/j. ajo.2017.09.016

8. Shajari M, Kolb CM, Petermann K, et al. Comparison of 9 modern intraocular lens power calculation formulas for a quadrifocal intraocular lens. $J$ Cataract Refract Surg. 2018;44(8):942-948. doi:10.1016/j.jcrs.2018.05.021

9. Gökce SE, Zeiter JH, Weikert MP, Koch DD, Hill W, Wang L. Intraocular lens power calculations in short eyes using 7 formulas. $J$ Cataract Refract Surg. 2017;43(7):892-897. doi:10.1016/j. jcrs.2017.07.004

10. Olsen T. Calculation of intraocular lens power: a review. Acta Ophthalmol Scand. 2007;85(5):472-485. doi:10.1111/j.17553768.2007.00879.x

11. Choi A, Kwon H, Jeon S. Accuracy of theoretical IOL formulas for Panoptix intraocular lens according to axial length. Sci Rep. 2021;11 (1):7346. doi:10.1038/s41598-021-86604-5

12. Dong EY, Joo CK. Predictability for proper capsular tension ring size and intraocular lens size. Korean J Ophthalmol. 2001;15(1):22-26. doi:10.3341/kjo.2001.15.1.22

13. Hayashi K, Hayashi H. Comparison of the stability of 1-piece and 3-piece acrylic intraocular lenses in the lens capsule. $J$ Cataract Refract Surg. 2005;31(2):337-342. doi:10.1016/j.jcrs.2004.06.042

14. Sato T, Shibata S, Yoshida M, Hayashi K. Short-term dynamics after single- and three-piece acrylic intraocular lens implantation: a swept-source anterior segment optical coherence tomography study. Sci Rep. 2018;8(1):10230. doi:10.1038/s41598-018-28609-1

15. Sugar A, Sadri E, Dawson DG, Musch DC. Refractive stabilization after temporal phacoemulsification with foldable acrylic intraocular lens implantation. J Cataract Refract Surg. 2001;27(11):1741-1745. doi:10.1016/S0886-3350(01)00894-X

16. Negishi K, Masui S, Torii H, Nishi Y, Tsubota K. Refractive stability of a new single-piece hydrophobic acrylic intraocular lens and corneal wound repair after implantation using a new automated intraocular lens delivery system. PLoS One. 2020;15(9):e0238366. doi:10.1371/journal.pone. 0238366
Central and CAS, and is the official journal of The Society of Clinical Ophthalmology (SCO). The manuscript management system is completely online and includes a very quick and fair peer-review system, which is all easy to use. Visit http://www.dovepress.com/ testimonials.php to read real quotes from published authors. 